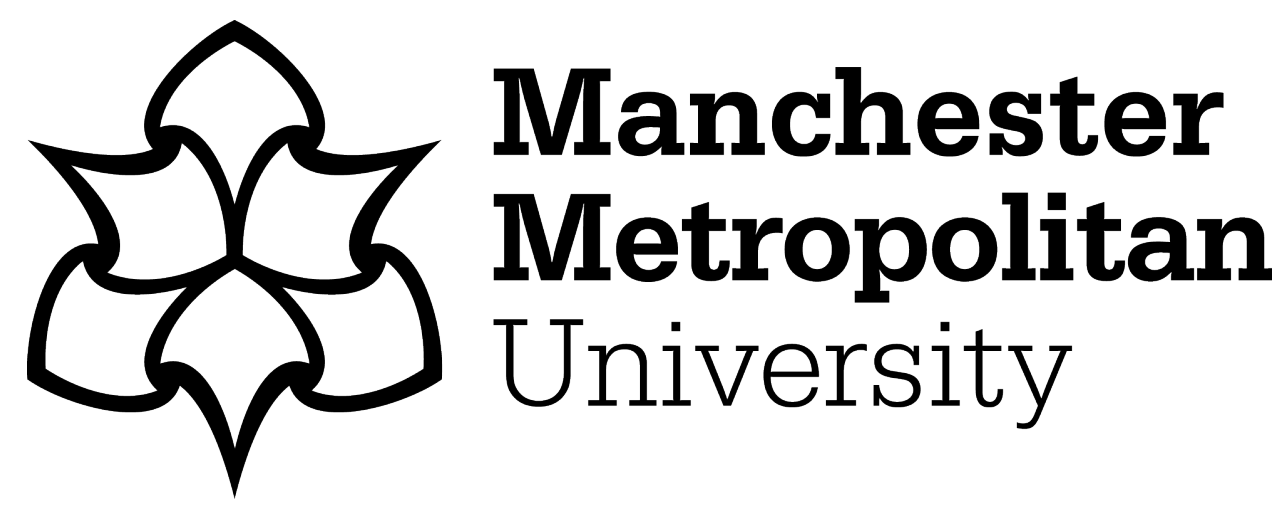

Persson, Sofia, Grogan, Sarah ORCID logoORCID: https://orcid.org/00000002-7510-765X, Dhingra, Katie and Benn, Yael ORCID logoORCID: https://orcid.org/0000-0001-7482-5927 (2019) "I don't mind being ugly but I don't wanna have skin cancer": a qualitative study of men over 35's attitudes to UV exposure and a facial morphing intervention. Psychology and Health, 34 (12). pp. 1486-1503. ISSN 0887-0446

Downloaded from: https://e-space.mmu.ac.uk/623032/

Version: Accepted Version

Publisher: Taylor \& Francis (Routledge)

DOI: https://doi.org/10.1080/08870446.2019.1622014

Please cite the published version 


\section{“I Don't Mind Being Ugly but I Don't Wanna Have Skin Cancer": A Qualitative Study of Attitudes to UV Exposure and a Facial Morphing Intervention in Men 35 Years and} Older

Objectives: Skin cancer is a growing problem globally. Older men have been largely ignored in previous research, even though men may generally be prone to riskier exposure to the sun than women. Past research suggests that appearance-focused techniques such as facial morphing can increase motivations to use sun protection among women of all ages, and younger men.

Design: was qualitative, consisting of individual interviews.

Method: was semi-structured interviews with 25 older men, to examine attitudes to UV exposure and reactions to a facial morphing intervention. Interviews were subjected to thematic analysis.

Results: Three themes were constructed: masculine UV exposure; appearance that's accepted; personal responsibility. The men did not identify gaps in their sun protection behaviour, and demonstrated a lack of concern about ageing and appearance. These attitudes translated into a lack of motivation for behaviour change due to ageing acceptance. However, motivation to change behaviour came from health concerns resulting from the intervention. Conclusions: The men experienced different motivations and barriers for sun protection use than women of similar ages. Facial morphing can be effective with older men, but may need to be reframed to focus on health implications and personal choice.

Keywords: Skin cancer; Facial Morphing; Older Men's Health; Behaviour Change; UV exposure 


\section{“I Don't Mind Being Ugly but I Don't Wanna Have Skin Cancer": A Qualitative Study of Attitudes to UV Exposure and a Facial Morphing Intervention in Men 35 Years and}

\section{Older}

68, 387 men are diagnosed with non-melanoma skin cancer each year; this number has increased continuously since the 1970s, and is expected to rise further until 2035 (Cancer Research UK, 2018c). The main cause of skin cancer is ultraviolet (UV) radiation, which can be behaviourally prevented, for instance by avoiding direct sunlight and using sun protection (NHS, 2017). As motivations behind sunbathing may be appearance-related (i.e., to achieve a tan), it is possible that highlighting costs to appearance rather than health may be more effective in reducing UV exposure (Jackson \& Aiken, 2000; Persson, Benn, et al., 2018). Qualitative and quantitative research on facial morphing techniques, which allow participants to see their face aged up to 72 years of age with and without UV damage, has indicated that this appearance-focused intervention can increase intentions to reduce UV exposure, and motivations to increase sun protection use (Owen, Grogan, Clark-Carter, \& Buckley, 2016; Persson, Benn, et al., 2018; Persson, Grogan, Dhingra, \& Benn, 2018).

The majority of previous research on appearance-focused interventions to reduce UV exposure has focused on people under the age of 35 years (Persson, Benn, et al., 2018; Williams, Grogan, Clark-Carter, \& Buckley, 2013). It therefore remains unclear whether a similar approach is equally effective with older people. As the peak age for skin cancer diagnosis for men in the UK is $69-75$, and men over 55 are the most common demographic group diagnosed with skin cancer (Cancer Research UK, 2016; Skin Cancer Foundation, 2016), it would appear relevant to target an older age groups as well. Qualitative research on women aged 35 years and older suggest that this group experiences age-specific attitudes to UV exposure and sun protection (Persson, Grogan, et al., 2018). Specifically, this group indicated that their primary motivation for sunbathing was not to achieve a tanned 
appearance, but to enjoy recreational time and reap the health benefits of the sun. Thematic analysis further revealed that the facial morphing intervention reinforced or increased motivations to adopt safe behaviour in the sun, by demonstrating the appearance-related costs of UV exposure and contrasting this with a positive, approach-type goal (i.e., the naturally aged photo).

The majority of research into appearance-focused interventions to reduce UV exposure has utilised female participants, mainly because women are more likely to engage in high-UV behaviours such as sunbathing or indoor tanning (Dodd et al., 2013). However, research indicates that men are less likely than women to adhere to sun safety recommendations, use sun protection, and are also less aware of skin cancer warning signs, resulting in what can be described as riskier sun exposure (Julian et al., 2016; Kasparian et al., 2009; Skin Cancer Foundation, 2016). This is in line with what the WHO (Baker et al., 2014) refers to as 'the men's health gap', where, despite overall social power in society, men's health globally is significantly worse than that of women. In the UK specifically, deaths from all major behavioural causes of mortality are more common among men than women (Robertson \& Gough, 2010; Sloan et al., 2010). This is broadly attributed to men's riskier lifestyle (leading to initial illness), and their responses to subsequent diagnosis, which include fewer visits to medical professionals and reduced perception of risk (Courtenay; 1999; 2000; Galdas et al., 2004; Julian et al., 2016; Sloan et al., 2010). These behaviours are generally thought to be in line with men's attempts to align their behaviour with hegemonic masculinity (i.e., culturally dominant norms for masculine behaviours), where men's health-related beliefs are a way of performing gender (Courtenay, 2000; Buchbinder, 2010). According to hegemonic masculinity theory (HMT; Connell \& Messerschmidt, 2005), complicity with hegemonic masculinity can result in men following a traditional discourse of self-reliance and detachment, as well as a rejection of health preoccupation, as this is construed as feminine 
(Buchbinder, 2010; Jeffries \& Grogan, 2012). This means that men will attempt to map their own behaviour onto what they perceive to be the culturally acceptable way of performing gender, but as most men cannot fully achieve this, individual varieties of masculinity will vary, with some being acceptable, and others marginalised (Connell \& Messerschmidt, 2005).

Previous research on UV photography and men has indicated that attitudes surrounding masculinities can impact on the effectiveness of appearance-focused interventions, in that men who exhibit higher levels of masculinity may be reluctant to engage with health improvement (Dwyer, 2014; Walsh \& Stock, 2012). Although HMT would posit that masculinity is not a single construct, it could be argued that measures of masculinity provide a useful index of the degree to which a man strives to align himself with the culturally dominant norm of masculinity. It appears that these types of interventions may need to be framed in a certain way (with a focus on personal choice) to be effective with men as well as women, particularly as males report being less concerned about the negative effects of the sun on appearance (Abroms et al., 2003). The relationship between masculine identities and risky health behaviour is not however straightforward. It appears that men can frame their engagement in pro-health behaviours in ways that do not threaten masculine norms, rejecting behaviour that are traditionally seen as damaging to one's health, e.g. smoking or unhealthy eating (Sloan et al, 2010; Robertson \& Williams, 2010). This further confirms the notion that all men behaviour according to hegemonic masculinity, either through adherence to, or rejection of typically masculine behaviour, thus creating multiple accepted (and marginalised) versions of masculinity. (Lohan, 2010; Sloan et al., 2010). This suggests that interventions to promote safe UV exposure can have the potential to be effective with men, even within the context of hegemonic masculinity currently prescribing a rejection of appearance concerns and certain health behaviours. As it appears that men's health-related attitudes, as well as their positioning in relation to hegemonic masculinity, will impact on 
MEN'S ATTITUDES TO UV EXPOSURE AND FACIAL MORPHING

their engagement with any intervention to reduce UV exposure, it is relevant for the current study to consider both these areas.

Qualitative research using facial morphing with younger men indicates that although they may be sceptical about this type of software, they remain shocked by the visible appearance effects of UV damage, prompting motivation to change behaviour and increase sun protection use (Williams et al., 2013). No research to date has assessed the effectiveness of this type of intervention, or barriers and motivations for sun protection use among men aged 35 years and older. Consequently, the current paper aims to investigate this group's general attitudes to UV exposure and sun protection, as well as their reactions to a facial morphing intervention. As facial morphing has not previously been examined with the current participant group, a qualitative methodology has the potential to examine factors that can impact on its effectiveness (e.g., prior attitudes to UV exposure), and ensure its effectiveness with a highly specific participant group (Dugdale et al., 2016; Michie et al., 2005). Interviews are a useful tool to understand how men account for their experiences of seeing their face morphed, and can be used to obtain an in-depth understanding of these reactions. Individual semi-structured interviews were chosen as they result in rich data, allowing participants to answer the questions in an in-depth and personal manner (Willig, 2013). The current study aims to address the following questions:

1. What are the attitudes (e.g., motivations and barriers) to UV exposure and sun protection among men aged 35 years and older?

2. How do men 35 years and older react and relate to a facial ageing intervention to reduce UV exposure, and how does this impact on their motivations to use sun protection?

\section{Method}




\section{The Research Team}

The research team was composed of four Psychology researchers, all female. The interviewer (first author) was a female PhD researcher in her mid-20s, Fitzpatrick (1975) Skin Type 3 (cream white: sometimes mild burn). The remaining authors were in their $30 \mathrm{~s}$ (Skin Type 2: white, fair; usually burn, tan less than average - with difficulty), 40s (Skin Type 3) and 60s (Skin Type 2). All were involved in the study design, data analysis and write up. Reflexive analysis was engaged in throughout the process of analysing and interpreting the data, following Finlay and Gough (2003).

\section{Participants}

There were 25 participants in total. The median age of participants was 47 ( $M=$ 46.80, $S D=6.95)$. The most common skin type (Fitzpatrick, 1975) was Type $2(32 \%)$, followed by Type 3 (28\%). 20\% of participants were type 4 (brown; rarely burn, tan with ease). $8 \%$ of participants described themselves as having Type 1 skin (white, very fair; always burn, never tan) or Skin Type 6 (black; never burn, tan very easily), and $4 \%$ as having type 5 skin (dark brown; very rarely burn, tan easily). The target for number of participants was guided by work in this area with older women and younger men (Persson, Grogan, et al., 2018), as well as the necessity of producing sufficient rich material to analyse to enable identification of patterns in the data (Terry et al., 2017). Participants were initially recruited by approaching people at an English university (e.g., members of staff from different university departments, and with varying job descriptions), and from this a snowball recruitment approach was used. All men spoke fluent English.

\section{Ethical Considerations}

The study had gained ethical approval though university Ethics Committee, and was conducted in accordance with The British Psychological Society (2018) guidelines; 
participants gave informed consent, were fully debriefed following the study, and data were anonymized by assigning pseudonyms to each participant.

\section{Apparatus}

APRIL $®$ age progression software (AprilAge Inc, 2017) was used to simulate reallife ageing up to 72 years of age, i.e., demonstrating what a person can hypothetically look like when they are 72 years of age. The aging algorithm used by APRIL $®$ is based on already published material on features of facial aging, as well as the developer's own 5-year study on the facial ageing of 7000 people of varying ethnicities and ages. This can be contrasted with traditional age progression software that are usually based on artistic renditions. APRIL ${ }^{\circledR}$ is statistically based, and produces two separate photos over a 55 second period for participants to compare: their faces aged as though they had not been exposing their skin to UV rays, or have been using sun protection, and their faces aged as though they had been exposing their skin to UV rays and had not been using sun protection, so that the differences in facial damage are visually represented side by side. Participants are also shown a 3D version of each photo, encouraging a life-like experience of the ageing by highlighting UV damage to the sides and neck. The software takes into account personal information about the participants (age and ethnicity), and it has been used in previous research concerning smoking and UV exposure, on samples of women and men of varying ages and ethnicities (e.g., Blashill et al., 2018; Grogan et al., 2011; Persson, Grogan, et al., 2018).

A laptop and web camera with the APRIL ${ }^{\circledR}$ software installed, and an audio recorder (mobile telephone) were used in this study. A research protocol was used, which was based on previous research with younger (Williams et al., 2012) and older (Persson, Grogan, et al., 2018) women, and modified to accommodate the aims of the current study (e.g., to investigate general attitudes to UV exposure as well as specific reactions to facial morphing) following discussions within the research team throughout the design of the study. 


\section{Procedure}

The study took place at an English university. All sessions took place in a private space to allow for discussions of private potentially sensitive and emotive issues (Manderson et al., 2006; Oliffe, 2010). Participants were first given the study information sheet, and were asked to sign consent forms. They were then asked to identify their Skin Type according to the Fitzpatrick (1975) test. Following this, the interviewer gave a brief introduction to the structure of the session which was as follows: initially participants had their photo taken, and age and ethnicity noted to set up the software. Once the software was set-up, the audio recorder was turned on, and participants were asked about their general attitudes to UV exposure, e.g., "Do you use sun protection?" and "Do you sunbathe?” This was before any facial morphing took place, to enable capturing participants' attitudes unaffected by the intervention. After these questions, the basics of facial morphing were explained (e.g., that the right-hand photo viewed on the computer screen would be with UV exposure and the left one without). Participants' faces were then morphed up until the age of 72 years and displayed on the computer screen. Natural reactions to this process were recorded, initially without asking any specific questions. Following this, participants were asked specific openended, non-directive questions about their reactions to the facial morphing, e.g. "How do you feel when you look at the photo on the right?", and its impact on their future intentions, e.g., "Does this photo motivate you to change your behaviour?", followed by "why/why not". Subsequent questions asked were based on participants' responses to the initial questions, ensuring that topics considered important by participants were covered. Finally, participants were asked if there was anything they would like to add, to ensure no crucial information was overlooked. The recorder was then turned off, and participants given a debrief sheet. 


\section{Data Analysis}

The audio-recorded interviews were transcribed verbatim, and the data were analysed by the first author through inductive thematic analysis (Braun \& Clarke, 2006; 2018), using NVivo Qualitative Data Analysis Software (QSR International, 2016). Data were coded on both a semantic and latent level, i.e., what participants said and the underlying meanings this carried were considered for the themes. A critical realist approach underpinned the analysis; it is thus acknowledged that the reality behind the findings exists independently of the researchers, but also that we as researchers have a role in constructing knowledge (Ormston et al., 2014). This study seeks to explain a number of phenomena related to appearancefocused interventions to reduce UV exposure, and not merely describe them, a key aspect of realism (Maxwell \& Mittapalli, 2010; Ritchie et al., 2013). The critical realist position does however acknowledge that knowledge is produced by social structure, and as such, cannot be considered truly objective (Willig, 2014).

In line with recommendations by Terry et al. (2017) and Braun and Clarke (2018), the initial step of the analysis was familiarisation with the data, involving a sense of curiosity with the material, directed at asking questions of the data. The second stage was generating codes which involved identifying relevant data within the data, and tagging these with words or short phrases, e.g., "use of sun protection". The third stage was identifying themes, which involved examining codes and associating data, and clustering these into meaningful patterns. The final stages involved reviewing and defining the themes, consisting of making sure the themes were coherent and related to one another, while still being separate. It also involved naming the themes.

Coding and themes were discussed and agreed upon by all the authors. Inductive thematic analysis was chosen as it allows rich themes to be generated the data, thus linking them strongly to the information provided by participants (Patton, 1990). In the quotes below, 
(.) is used to denote a pause, and pseudonyms, aged and skin types are provided in parentheses next to each quote.

\section{Results}

Three interconnected themes appeared to carry most meaning in the discussions. See Figure 1 for theme matrix.

1. Masculine UV exposure

2. Appearance that's accepted

3. Personal responsibility

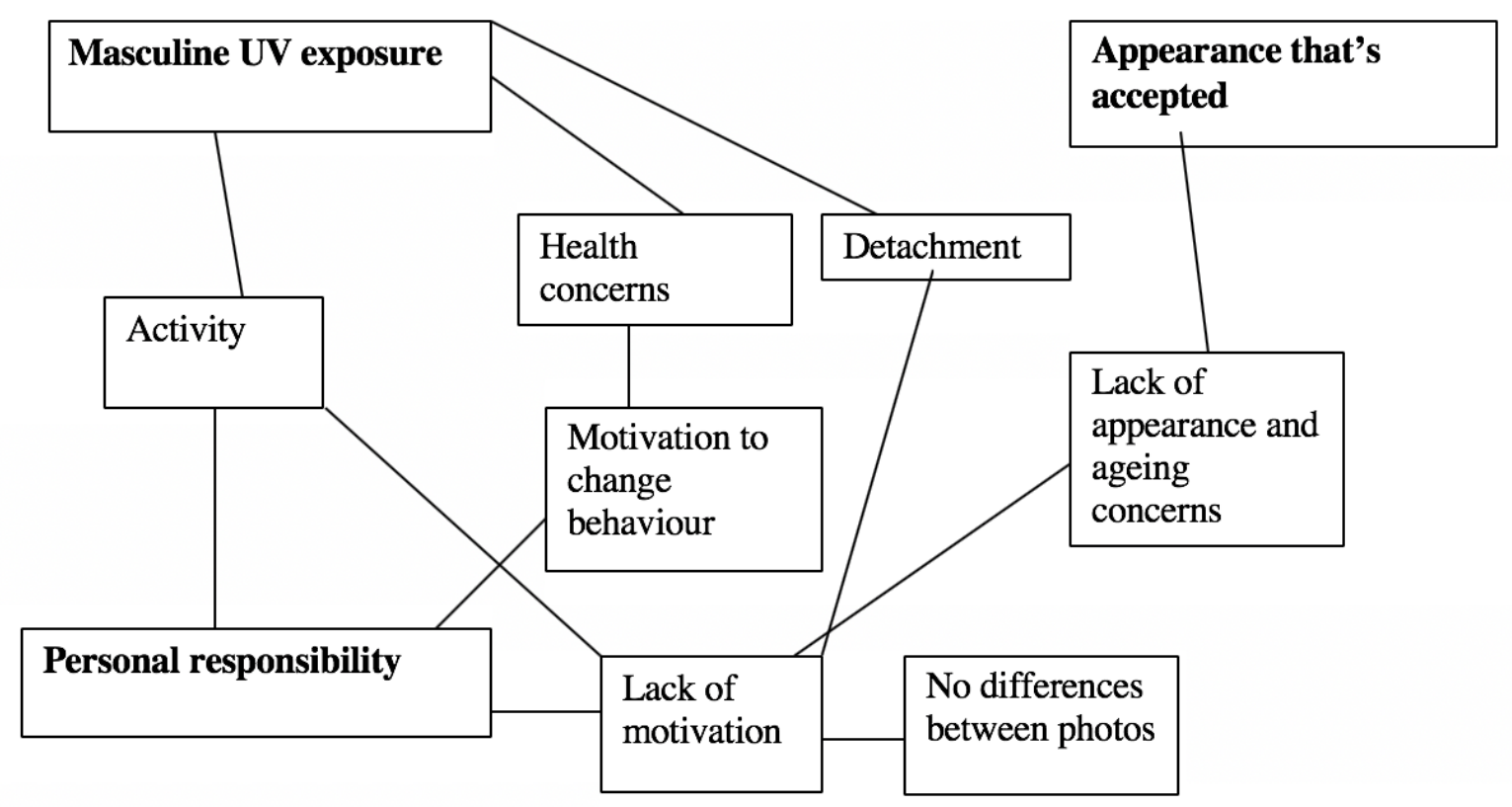

Figure 1. Thematic matrix

\section{Theme 1: Masculine UV exposure}

A contributing factor as to why male participants have been under-researched in studies of UV exposure is that they are less likely to fall into traditional high-risk groups such as sunbathers or indoor tanners (Stapleton et al., 2015). However, research suggests that although men may not overtly engage in behaviours aimed at achieving a tanned appearance, 
their sun exposure behaviours are in some instances riskier than that of women, as they may have greater sun exposure and employ less sun protection strategies (Julian et al., 2016; Skin Cancer Foundation, 2016). This was reflected in the current sample, where the men rejected behaviours traditionally associated with achieving a tan in favour of various forms of physical activity.

"I like the sun and I want to go where the sun is on holiday especially, but I wanna be active in this... you know... I wanna be doing something, like walking or some kind of sport" (Paul, age 36, Skin Type 3)

Sunbathing was perceived as a "pointless and vain activity" (Oscar, age 52, Skin Type 2), which they did not want to be seen taking part in. Older men's rejection of activities regarded as vain in favour of physical activity has also been demonstrated by Liechty et al. (2014). The rejection of risky sun exposure by representing the practice and those identifying with it as "vain" is similar to research into why certain people reject indoor tanning practices (Taylor, Lamont \& Murray, 2017).

A tanned appearance was sometimes commented on as a "nice by-product" (Louis, age 49, Skin type 4) of undertaking other activities in the sun, but not a primary motivation:

“I get bored easily I guess but I wouldn't go just... to get a suntan, I wouldn't go for the sunbathing, I would go maybe to play rackets you know on the beach or... volley, beach volley but... or swim but not necessarily to... on purpose to sunbathe" (Martin, age 41, Skin Type 4)

As time spent in the sun was mainly perceived in terms of activities that were undertaken, and not with the motivation of achieving a tanned appearance, these men did not identify personal gaps in sun protection, e.g. asserting that they have "a complexion that can sort of take... the sun" (Lyle, age 44, Skin Type 4) and "I don't think the sun's that strong" (Bob, age 53, Skin Type 3). It is possible that this was because sun-damage was associated with 
actively sunbathing and desiring a tan, which they did not do. Likewise, it is possible that the men were aware of current sun safety recommendations, without necessarily accepting them as truth. A contributing factor to this could be that health recommendations do sometimes change, and that messages about sun safety and vitamin D can at times appear contradictory (NHS, 2016; Persson et al., 2018).

Although these men simultaneously described situations that could objectively be perceived as high-risk in terms of sun exposure, e.g., "I've been fairly relaxed and blasé about the risks" (Jakob, age 49, Skin Type 5) and "When I'm on holiday [I] go and lounge by the pool and by the beach from like... early in the morning to 6 o'clock" (Lyle, age 44, Skin Type 4), they failed to acknowledge this as being problematic:

"I would never dream of putting suntan... lotion on in this country, in the summer" (Bob, age 53, Skin Type 3)

Where women of similar ages identified gaps in sun protection use, these men generally did not acknowledge this behaviour as dangerous or damaging to their health (Persson, Grogan, et al., 2018). This is in line with previous findings that men are generally less likely than women to perceive themselves to be at risk for health problems (Courtenay, 2000). They also considered other healthy lifestyle options they had chosen as a reason to believe they would not be at risk. It is possible that they did not genuinely believe this, but employed a sense of positivity to avoid worry:

"I think no I'll be fine, I'll be fine; I think I'm sort of quite an active person, I've always been quite healthy and kind of think I'll be fine you know, I won't be the person... that gets skin cancer or anything like that, I'll be okay" (Paul, age 36, Skin Type 3)

They spoke with a level of detachment about their UV exposure and sun protection, without assigning a large amount of personal meaning to these behaviours. The men discussed pros 
[e.g. "to feel healthier" (Miles, age 61, Skin Type 3)] and cons [e.g., "skin cancer and... melanomas, and things like that" (Trevor, age 46, Skin Type 4)] of UV exposure, which was similar between different ages and skin types. However, as previously outlined, they did not appear to consider the negative effects of UV exposure as a motivator to change their own behaviour:

"I guess in acceptance that [sun protection] is the right thing to do, um... but I don't... I don't worry about it myself particularly" (Ashton, age 38, Skin Type 2)

It could be argued that this sense of optimism regarding future sun damage is unrealistic as the number of new skin cancer incidences previously discussed should encourage people to 'worry' about sun protection use. The men were particularly interested in the technicalities around sun-protection application and the market for sun protection products, without applying it to their own lives and behaviours. UV protection was viewed as a "market there, that people can... be exploited for" (Louis, age 49, Skin Type 4), and they thought that it would be impossible to determine which, if any, of the products were effective for use:

"Sun protection is not always great, there's a huge variety of products... and which one's the best, is anybody's guess" (Alistair, age 45, Skin Type 2)

Although these men are partially correct in that sun screen products do exist in a market economy with developers profiting from selling products, this does not mean that they are sold under false pretences. It is possible that the men used these rather simplistic arguments as a way of avoiding personal responsibility for the health consequences of UV exposure. As the European Commission has clear guidelines on regulations for sunscreen labelling, it is indeed possible to determine which products will protect most effectively against the sun (European Commission: Growth, 2017). When the men did use sun protection, it was mainly during physical activities such as gardening, jogging, or playing sports, which suggests that protecting their skin was only salient in a small number of 
situations, e.g., sun protection being "non-existent apart from when I'm in the high mountains" (Trevor, age 46, Skin Type 2).

The men's detached attitudes to sun protection were broadly similar to findings by Davidson and Meadows (2010), who suggest that like younger men, older men have a “should care/don't care" approach to personal health, where they are aware of health advice (should care) but choose to not adhere to it (don't care). More broadly, this also reflects the intention-behaviour gap, present among both genders (Gollwitzer \& Sheeran, 2006). A similar pattern has been found through interviews with younger men, where discussions around behaviour change and appearance have reflected a traditional discourse of masculinity centred on detachment and self-reliance (Grogan, 2017). Gender stereotypes were sometimes consciously commented on by the men, e.g., "I think for men it's a bit different" (Lyle, age 44, Skin Type 4) as in the case of sun protection. It appeared to be a convenient strategy for avoiding further consideration of gaps in sun protection use, where the men accepted gender stereotypes as a justification for not modifying their behaviours:

"Someone was saying today about men don't like putting sun cream on because it feels really sticky... and I always hated putting it on because of that" (Daniel, age 35, Skin Type 1)

Finally, it is possible that the men did not see their limited sun protection use as a problem, as not only are the benefits generally delayed, but there is also uncertainty as to what the delayed consequences of not performing the behaviour will be, partially because of the benefits being in the distant future, but also because not everyone who expose themselves to the sun will get skin cancer (Cancer Research UK, 2018a; Chapman, 2005).

\section{Theme 2: Appearance that's accepted}

The discussions about UV exposure and sun protection led the men to consider general appearance and aging. Unsurprisingly, they were generally unconcerned about their 
physical appearance, and the effect that ageing might have on this. A large body of qualitative and quantitative research indicates that men of all ages are less concerned about physical appearance than are women of similar ages, a likely result of women being judged more according to their appearance, in all areas of life (Grogan, 2017). This has also been supported by in-depth interviews with older and younger samples where aging is viewed in positive terms, and the ageing body viewed as utilitarian (Halliwell \& Dittmar, 2003; Liechty et al., 2014). This reflects what has been referred to as 'the double standard of aging' (Halliwell \& Dittmar, 2003), where men's aging is viewed neutrally or positively by themselves and society, whereas women's aging is viewed negatively. It might therefore be that these men have made a rational choice in limiting their appearance concerns, as they are unlikely to be 'punished' by society for this:

"I guess being male as well... there is an association quite a lot of cultures with being older and craggier as having some sort of wisdom" (Mikael, age 57, Skin Type 1) The men also considered attitudes to a tanned appearance:

"It doesn't matter, you know there's worse things in life than the way you look..." (Oscar, age 53, Skin Type 2)

They were keen to emphasize that appearance was not an important aspect of how they viewed themselves, and that they were happy with, or accepted the way they looked, feeling no need to employ strategies such as tanning to improve their appearance, e.g. "I don't tend to have difficulty with my appearance" (Mats, age 41, Skin Type 4).

Although this lack of concern about personal appearance could reduce the effectiveness of appearance-focused interventions and thus fail to reduce UV exposure or increase UV protection practices, it seemed as if these attitudes protected some of the men from UV exposure to begin with, particularly as they regarded sunbathing as a vain activity. 
However, it remains unclear whether this would translate into avoiding direct sun exposure altogether, or simply avoiding active displays of sunbathing.

“There's something about me wanting to avoid being overtly vain... you know about sun tanning so I wanted to kind of embrace not... sun tanning” (Daniel, age 35, Skin Type 1)

Following the facial morphing, it appeared that even when the men agreed that the UV-photo looked worse than the naturally aged photo, some of them claimed to not particularly mind whichever photo they would end up looking like. This was not necessarily confined to the consequences of UV exposure, but part of a generally laissez-faire approach to personal appearance:

"If I'm honest it wouldn't necessarily bother me.... um.... which one (of the photos) I look like, I mean you know... I get up and wash my hair and let it dry and it falls how it falls" (Louis, age 49, Skin Type 4)

The naturally aged photo was rarely commented on by the men, suggesting that they did not regard the naturally aged photo as an approach-type goal, and thus not a primary motivation for behaviour change. The lack of focus on the naturally-aged photo seemed to be motivated by their desire not to appear vain, as well as a reluctance to change their lifestyle:

"I'm not about to go and ... and alter my behaviour to... try and retain an appearance of looking more youthful than I naturally might if I continue to behave as I do" (Mats, age 41, Skin Type 4)

\section{Theme 3: Personal responsibility}

The facial morphing process also led the men to discuss general ways of living, and the lifestyle choices they were currently making within the context of long-term consequences, where they accepted responsibility for the choices they had made. General ageing was not a cause of concern, but perceived as a natural result of a life lived in a certain way: 
"I'm quite happy to live with the consequences of what... as... what I've done or what I, you know, or what the situations I've put myself in that's that's part of life..." (Mats, age 41, Skin Type 4)

The facial morphing process led the men to discuss "general health" (Rudy, age 40, Skin Type 6) in relation to UV exposure as well as other areas of life, and these discussions were often framed in terms of personal responsibility. It was clear that the main concern of the UV photo was the underlying health issues associated with the sun damage, not the physical appearance in itself. This suggests that facial morphing can prompt relevance of the issue of sun damage for men, but perhaps not through direct appearance concerns. As highlighted by the below quote, there is an acceptance of the appearance-related consequences of UV exposure, but a desire to be responsible for avoiding skin cancer:

"I don't mind being ugly but I don't wanna have skin cancer" (Ashton, age 38, Skin Type 2)

Motivation to change behaviour appeared to be less driven by appearance concerns and more by general health concerns; this is hardly surprising considering the previously discussed themes of health and activity focus, and lack of appearance importance, e.g., looking like the UV damaged photo would not be problematic "unless, it was you know, there was a medical reason" (Louis, age 49, Skin Type 2). The photo aged with sun damage appeared to only carry meaning if it represented underlying health issues, thus prompting the men to take personal responsibility for behaviour change:

"I'm not bothered about the wrinkles and such things like that but those blemishes and marks look.... (.) they look like they could be nasty" (Trevor, age 47, Skin Type 4) The men also commented on the importance of the comparison aspect between the two photos, a key advantage of the facial morphing software: 
"For anybody who's looking at these two images to compare and see what might happen if you expose or if you don't exposure yourself... so those are some of the positives that I could see from this um exercise which is good" (Rudy, age 40, Skin Type 6)

This comparison aspect appeared to promote a sense of personal responsibility for their health, as it presented the participant with two options of their future self, thus increasing self-efficacy surrounding sun protection:

"The fact that you know there is element of, you know, choice here... um... is.... is obviously um compelling, it makes it much more vivid, and also a sense, gives you a sense of responsibility about it" (Jakob, age 49, Skin Type 5)

Finally, some men suggested that (even when they did notice objective differences between the photos) the UV damaged photo did not look considerably worse than the naturally aged photo:

"But even the one without sun protection and everything else isn't particularly horrific" (Alistair, age 45, Skin Type 2)

It is therefore possible that the distinct appearance focus of facial aging interventions may, in some cases, deter men from engaging with behaviour change, as it activates gendered attitudes about ageing concerns and vanity. However, facial morphing may have been more effective with these men if it was reframed as being representative or a proxy of health issues, that the men may be prompted to accept personal responsibility for.

\section{Discussion}

Men's lack of concern about the appearance-related consequences of ageing has been previously demonstrated in qualitative research by Sloan et al. (2010); this has also been observed in qualitative research on reactions to a facial morphing intervention among younger men, who generally lacked concerns about the consequences of UV exposure on 
ageing and appearance (Loosemore \& Grogan, 2015). When the current sample did express motivation to adopt safer behaviour in the sun, this was generally driven by the underlying health concerns of the UV exposed photo, which again relates to men generally perceiving their bodies in terms of functionality rather than something to be displayed (Halliwell \& Dittmar, 2003). The above would also explain the gender differences in the age group, as women are traditionally encouraged to objectify their own body in ways men are not (Fredrickson \& Roberts, 1997; Grogan, 2017). Encouragingly, this does suggest that men are not unconcerned about their personal health. Given the focus of the present intervention, it is however possible that the men in the current sample only discussed health concerns as it was the more 'masculine' option compared with appearance concerns. The above suggest that facial morphing could be effective in reducing UV exposure among men, but it is possible that efficacy would be greater if emphasis was put on the health implications of the visual information provided.

Some men expressed a lack of motivation for behaviour change following the facial morphing, partially because of a lack of appearance concern. It may also be related to findings by Davidson and Meadows (2010), where older men in their sample justified their lack of engagement with health services with scepticism about the medical profession as a whole. It is however unclear whether this scepticism is genuine, or used as an excuse to avoid engaging with medical advice. This suggests that even when men have health-oriented motivations, they cannot be acted on at the expense of masculinity (Gough, 2007). This is in sharp contrast with women of a similar age, where appearance concerns were a main factor in behaviour change, and the naturally aged photo construed as a goal to work towards (Persson, Grogan, et al., 2018) It is possible that an intervention such as facial morphing may need to be adapted depending on the target demographic. However, as noted by Sloan et al. (2010) and Gough (2010), a main challenge to this will be to adapt this health advice to men, whist 
also avoiding perpetuating the very stereotypes of masculinity that contribute to men's poorer health to begin with. In the long-term, a more sustainable solution would be to promote the redefinition of masculinity, and ultimately the loosening of gender roles in society, so that men and women alike can enjoy better physical health (Buchbinder, 2010).

In research on UV photography, Dwyer (2014) suggests that promoting personal choice may enhance the efficacy of behaviour change interventions among men as it does not challenge norms of masculinity, a point that has also been argued by Sloan et al. (2010). It would be possible to further highlight the issue of personal choice in a facial morphing intervention, as the comparison aspect between the two photos was already commented on by some of the men as containing a choice, thus creating a sense of personal responsibility, which appears to be important to men of this age. Moreover, Deeks et al. (2009) argue that older men may be more prone to requesting health preventative information than younger men, suggesting that a well-designed intervention to reduce UV exposure could be received well by this age group. Finally, men can, in some instances, re-frame behaviours traditionally seen as feminine (e.g., weight concerns or adopting a healthy diet) to suit masculine norms (Sloan et al., 2010). It is therefore possible that the same could be done with sun protection use.

Finally, there appears to be similarities between the genders with regards to the importance of situation salience and information clarity, in that like women of similar age (Persson, Grogan, et al., 2018) men in the current study reported using sun protection in particular situations viewed as high-risk, such as mountaineering or skiing; this is promising as it suggests that it is possible to counteract masculine attitudes regarding sun protection use, by promoting goal salience. This could be achieved by combining a facial morphing intervention with implementation intentions, as these have shown great promise in prompting a wide range of health-related behaviour changes (Gollwitzer \& Sheeran, 2006). 


\section{Strengths, Limitations and Future Directions}

The study benefitted from a large sample size, and the semi-structured interviews allowed for the men to expand on issues they felt to be important. There was also a wide array of skin types, which is particularly important as people with darker skin tones are still susceptible to skin cancer (Cancer Research UK, 2018a). A possible limitation of the study was that men may have been reluctant to appear less masculine with a female interviewer, in line with past research into interviewer effects suggesting that the gender of the interviewer may impact on interviewee answers in the context of social desirability (Lavrakas, 2008). Some researchers (e.g., Grogan \& Richards, 2002; Williams \& Heikes, 1993) have however suggested that men may be more comfortable disclosing intimate information to a female interviewer, than they would with a male interviewer, indicating that the set-up of the current study may have been less of a limitation, and more of a strength. However, as no studies up to date have examined interviewer effects within the context of appearance-focused interventions to reduce UV exposure, it is not possible to determine what impact interviewer gender had on the current set of accounts. Future work therefore benefit from comparing data collected from female and male researchers. Another limitation is the varied level of morphing between participants; younger men's photos would have had significantly more years added to them than the older men's. However, reactions and evaluations of the photos were similar throughout the age span as has been reflected in quotes throughout the text, suggesting this did not have considerable effect on the experiences of the intervention. There also appeared to be variability of results between skin tones; those with darker skin tones noticed a smaller difference between the photos than those of lighter/medium skin tones; this therefore calls for further investigation. All the men were UK-based, and the vast majority employed at a British University, so results need to be transferred to other groups with caution. 
Future research would benefit from considering aspects such as participants' adherence to norms of masculinity, as this has been previously found to be a moderator in the effectiveness of health interventions generally, and appearance-focused interventions to reduce UV exposure specifically (Dwyer, 2014). It would also be beneficial to include men of a wider array of socio-economic backgrounds, as lower SES has generally been associated with poorer health outcomes, and also interacts with gender and ethnicity in a health context (Galdas et al., 2005; Michie et al., 2011). Finally, a key limitation was that the current study did not document the sexuality of the men, something that future research should consistently aim to do. Past research suggests that gay male subculture is significantly more "appearance potent" than the dominant heterosexual male culture, and that gay men may be more concerned about their appearance than their heterosexual counterparts (e.g., Grogan, 2017; Jankowski et al., 2014).

\section{Reflexive Analysis}

The researchers have made every effort to present the men's account in an objective and fair manner. The first researcher is undertaking a $\mathrm{PhD}$ in Health Psychology, and has a personal interest in behaviour change, body image, and gender roles. She has engaged with the facial morphing intervention, and reflected on this experience in relation to motivations to use sun protection. However, as she is under 35 years old and female, she will have experienced different motivations and barriers to UV exposure and sun protection use than the current all-male sample. This is particularly relevant in relation to the discussions of masculinity and gendered norms for sun protection use. As there is no comparison group, it is not possible to determine whether the men would have behaved differently with a male interviewer of a similar age. This similarly applies to the remainder of the research team, although they were able to relate to the sample age-wise, as all being over 35 years. An additional strength of the research team is their expertise and research interest in body image 
MEN'S ATTITUDES TO UV EXPOSURE AND FACIAL MORPHING

and appearance concerns, something that hopefully facilitated an in-depth analysis of the men's accounts.

\section{Conclusions}

In conclusion, this qualitative research provides a unique insight into a demographic group that has been largely overlooked in previous research on UV exposure: men aged 35 years and older. It benefits from considering how general attitudes to UV exposure, sun protection, and masculinity may impact the efficacy of appearance-focused interventions such as facial morphing. Inductive thematic analysis revealed four relevant themes: masculine UV exposure, appearance that's accepted; and personal responsibility. Men's motivations for UV exposure were primarily associated with physical activity, and they were reluctant to identify gaps in their sun protection use. In line with past research, they accepted their personal appearance, and took personal responsibility for the consequences of their behaviour, which at times meant increased motivation to reduce UV exposure due to health concerns. These attitudes were directly related to the men's reactions to the facial morphing, where those who did express motivation to change their behaviour were primarily motivated by health concerns rather than appearance, and those who were not motivated to change behaviour accepted the physical consequences of aging and remained unconcerned about the dangers of UV exposure. This suggests that appearance-focused interventions can be successful in reducing UV exposure in this group, but may need to be adopted to promote the underlying health issues demonstrated by the differences between the two photos.

\section{References}

Abroms, L., Jorgensen, C., Southwell, B, Geller, A. \& Emmons, K. (2003). Gender differences in young adults' beliefs about sunscreen use. Health Education Behavior, $30,1,29-43$. 
MEN'S ATTITUDES TO UV EXPOSURE AND FACIAL MORPHING

AprilAge Inc. (2017). April ${ }^{\circledR}$ face aging software. Retrieved from https://aprilage.com/products/april-face-aging-software/

Baker, P., Dworkin, S., Tong, S., Banks, I., Shand, T., \& Yamey, G. (2014). The men's health gap: Men must be included in the global health equity agenda. Retrieved from http://www.who.int/bulletin/volumes/92/8/13-132795/en/

Blashill, A. J., Rooney, B., Luberto, C. M., Gonzales, M., \& Grogan, S. (2018). A brief facial morphing intervention to reduce skin cancer risk behaviors: Results from a randomized controlled trial. Annals of Behavioral Medicine, 52, S478-S478.

Braun, V. \& Clarke, V. (2006). Using thematic analysis in psychology. Qualitative Research in Psychology, 3, 2, 77-101.

The British Psychological Society. (2018). Code of ethics and conduct. Retrieved from https://www.bps.org.uk/news-and-policy/bps-code-ethics-and-conduct

Buchbinder, D. (2010). A grand illusion: Masculinity, "passing” and men's health. In B. Gough \& S. Robertson (Eds.), Men, masculinities \& health: Critical perspectives. Basingstoke: Palgrave Macmillan.

Cancer Research UK. (2018a). About skin cancer. Retrieved from https://www.cancerresearchuk.org/about-cancer/skin-cancer

Cancer Research UK. (2018b). Skin cancer - after surgery. Retrieved from https://www.cancerresearchuk.org/about-cancer/skincancer/treatment/surgery/surgery-for-larger-skin-cancers/after-surgery

Cancer Research UK. (2018c). Skin cancer - statistics. Retrieved from http://www.cancerresearchuk.org/about-cancer/type/skin-cancer/

Chapman, G. B. (2005). Short-term cost for long-term benefit: Time preference and cancer control. Health Psychology, 24(4), S41-S48. doi:10.1037/0278-6133.24.4.S41 
MEN'S ATTITUDES TO UV EXPOSURE AND FACIAL MORPHING

Connell, R. W., \& Messerschmidt, J. W. (2005). Hegemonic masculinity: Rethinking the concept. 19(6), 829-859. doi:10.1177/0891243205278639

Courtenay, W. (2000). Endangering health: a social constructionist examination of men's health beliefs and behaviors. Psychology of men and masculinity, 1(1), 4-15, doi: $10.1037 / 1524-9220.1 .1 .4$

Davidson, K., \& Meadows, R. (2010). Older men's health. In Gough, B, \& Robertson, S (Eds.), Men, Masculinities \& Health: Critical Perspectives. Basingstoke, UK: Palgrave Macmillan Ltd.

Deeks, A., Lombard, C., Michlemore, J., \& Teede, H. (2009). The effects of gender and age on health related behaviors. BMC Public Health. 9 (213). doi: 10.1186/1471-2458-9

Dodd, L. J., Forshaw, M. J., \& Williams, S. (2013). Indoor Tanning within UK Young Adults: An Extended Theory of Planned Behaviour Approach. ISRN Preventive Medicine, 2013, 394613. http://doi.org/10.5402/2013/394613

Dwyer, L. A. (2014). Enhancing UV photography among men with choice-promoting information. (3607894 Ph.D.), The George Washington University, Ann Arbor. Retrieved from ProQuest Dissertations \& Theses A\&I database. 213

European Commission: Growth. (2017). Sunscreen products. Retrieved from https://ec.europa.eu/growth/sectors/cosmetics/products/sunscreen_en on 18/9 2017.

Finlay, L \& Gough, B. (2003). Reflexivity: A practical guide for researchers in health and social sciences. Oxford: Blackwell.

Fredrickson, B. \& Roberts, T. (1997). Objectification theory: toward understanding women's lived experiences and mental health risks. Psychology of Women Quarterly, 21(2), 173-206, doi: 10.1111/j.1471-6402.1997.tb00108.x

Gast, J. \& Peak, T. (2011). 'It used to be that if it weren't broken and bleeding profusely, I 
MEN'S ATTITUDES TO UV EXPOSURE AND FACIAL MORPHING

would never go to the doctor': Men, masculinity, and health. American Journal of Men's Health, 5(4), 318-331.

Gollwitzer, P. \& Sheeran, P. (2006). Implementation intentions and goal achievement: a meta-analysis of effects and processes. Advances in Experimental Social Psychology. 38, 69-119. doi: https://doi.org/10.1016/S0065-2601(06)38002-1

Gough, B. (2007). Try to be healthy, but don't forgo your masculinity: Deconstructing men's health discourse in the media. Social Science and Medicine, 63, 2476-2488, doi: $\underline{10.1016 / j . s o c s c i m e d .2006 .06 .004}$

Gough, B. (2010). Promoting masculinity over health. In Gough, B, \& Robertson, S (Eds.), Men, Masculinities \& Health: Critical Perspectives. Basingstoke, UK: Palgrave Macmillan Ltd.

Grogan, S. (2017). Body image: Understanding body dissatisfaction in men, women and children (third edition). London: Routledge.

Grogan, S., Flett, K., Clark-Carter, D., Conner, M., Davey, R., Richardson, D., \& Rajaratna, G. (2011). A randomized controlled trial of an appearance-related smoking intervention. Health Psychology, 30, 6, 805-809. doi: http://dx.doi.org/10.1037/a0024745

Grogan, S. \& Richards, H. (2002). Body Image: Focus Groups with Boys and Men. Men and Masculinities, 4, 219-233.

Guest, G., Bunce, A. \& Johnson, L. (2006). How many interviews are enough - an experiment with data saturation and variability. Field Methods, 18(1), 59-82.

Halliwell, E., \& Dittmar, H. (2003). A qualitative investigation of women's and men's body image concerns and their attitudes towards ageing. Sex Roles. 49(11), 675-684, doi; 10.1023/B:SERS.0000003137.71080.97 
MEN'S ATTITUDES TO UV EXPOSURE AND FACIAL MORPHING

Holman, D. M., Berkowitz, Z., Guy Jr, G. P., Hawkins, N. A., Saraiya, M., \& Watson, M. (2015). Patterns of sunscreen use on the face and other exposed skin among US adults. Journal of the American Academy of Dermatology, 73(1), 83-92

Iacobucci, G. (2018). NHS waiting times: number of patients waiting 18 weeks for treatment rises sharply. BMJ. 361, k2114.

Jankowski, G. S., Fawkner, H., Slater, A., \& Tiggemann, M. (2014). “Appearance potent”? A content analysis of UK gay and straight men's magazines. Body image, 11(4), 474481

Jeffries, M., \& Grogan, S. (2012). 'Oh, i'm just, you know, a little bit weak because i'm going to the doctor's': Young men's talk of self-referral to primary healthcare services. Psychology \& Health, 27(8), 898-915. doi:10.1080/08870446.2011.631542

Jackson, K. M., \& Aiken, L. S. (2000). A psychosocial model of sun protection and sunbathing in young women: The impact of health beliefs, attitudes, norms, and selfefficacy for sun protection. Health Psychology, 19(5), 469-478. doi:10.1037/02786133.19 .5 .469

Kasparian, N., McLoone, J. \& Meiser, B. (2009). Skin cancer-related prevention and screening behaviours: a review of the literature. Journal of Behavioural Medicine. 32(5), 406-428. doi: 10.1007/s10865-009-9219-2

Lavrakas, P. J. (2008). Encyclopedia of survey research methods Thousand Oaks, CA: Sage Publications, Inc. doi: 10.4135/9781412963947

Lawler, S., Sugiyama, T., \& Owen, N. (2007). Sun exposure concern, sun protection behaviors and physical activity among Australian adults. Cancer Causes \& Control, 18(9), 1009-1014

Liechty, T., Dahlstrom, L., Sceinson, K., Stafford Son, J. \& Rossbow-Kimball, B. (2014). Canadian men's perceptions of leisure time, physical activity, and the ageing body. 
MEN'S ATTITUDES TO UV EXPOSURE AND FACIAL MORPHING

Qualitative Research in Sport, Exercise and Health, 6(1), 20-44, doi: $10.1080 / 2159676 X .2012 .712990$

Lohan, M. (2010). Developing a critical men's health debate. In Gough, B, \& Robertson, S (Eds.), Men, Masculinities \& Health: Critical Perspectives. Basingstoke, UK: Palgrave Macmillan Ltd.

Loosemore, E. \& Grogan, S. (2015). Men's accounts of Reactions to two sources of information on negative effects of UV exposure: facial morphing and a health promotion sheet. International Journal of Men's Health, 14(2), 182-195, doi: 0.3149/jmh.1402.182 • eISSN/1933-0278

Manderson, L., Bennett, E., \& Andajani-Sutjahjo, S. (2006). The social dynamics of the interview: age, class, and gender. Qualitative health research, 16(10), 1317-1334

Maxwell, J., \& Mittapalli, K. (2010). Realism as a stance for mixed methods research. In A. Tashakkori \& C. Teddlie (Eds.), Sage handbook of mixed methods in social and behavioral research (2 ed.). Thousand Oaks, California: SAGE Publications, Inc.

Michie, S., Jochelson, K., Markham, W. \& Bridle, C. (2008). Low income groups and behaviour change interventions: a review of intervention content and effectiveness. London: Kings Fund.

NHS. (2016). The new guidelines on vitamin $d$ - what you need to know. Retrieved from https://www.nhs.uk/news/food-and-diet/the-new-guidelines-on-vitamin-d-what-youneed-to-know/

NVivo qualitative data analysis Software; QSR International Pty Ltd. Version 11, 2016

O’Brien, R., Hunt, K., \& Hart, G. (2005). 'It's caveman stuff, but that is to a certain extent how guys still operate': men's accounts of masculinity and help seeking. Social science \& medicine, 61(3), 503-516 
MEN'S ATTITUDES TO UV EXPOSURE AND FACIAL MORPHING

Oliffe, J. (2010). Bugging the cone of silence with men's health interviews. In Gough, B, \& Robertson, S (Eds.), Men, Masculinities \& Health: Critical Perspectives. Basingstoke, UK: Palgrave Macmillan Ltd.

Ormston, R., Spencer, L., Barnard, M., \& Snape, D. (2013). The foundations of qualitative research. In J. Ritchie, J. Lewis, \& C. Nicholls (Eds.). Qualitative research practice: A guide for social science students and researchers. London: Sage.

Owen, A. L., Grogan, S., Clark-Carter, D., \& Buckley, E. (2016). Effects of an appearancefocussed versus a health-focussed intervention on men's attitudes towards uv exposure. International Journal of Men's Health, 15(1).

Ritchie, J., Lewis, J., \& Nicholls, C. (Eds.). (2013). Qualitative research practice: A guide for social science students and researchers. London: Sage.

Robertson, S. \& Gough, B. (2010). What is the point of this book? In Gough, B, \& Robertson, S (Eds.), Men, Masculinities \& Health: Critical Perspectives. Basingstoke, UK: Palgrave Macmillan Ltd.

Robertson, S., \& Williams, R. (2010). Men, public health, and health promotion. In Gough, B, \& Robertson, S (Eds.), Men, Masculinities \& Health: Critical Perspectives. Basingstoke, UK: Palgrave Macmillan Ltd.

Persson, S., Benn, Y., Dhingra, K., Clark-Carter, D., Owen, A. L., \& Grogan, S. (2018). Appearance-based interventions to reduce uv exposure: A systematic review. British Journal of Health Psychology, 23(2), 334-351. doi:10.1111/bjhp.12291

Persson, S., Grogan, S., Dhingra, K., \& Benn, Y. (2018). 'It's bit of an eye opener' - a qualitative study of women's attitudes towards tanning, sun protection and a facial morphing intervention. Psychology \& Health, 33(3), 381-397. doi:10.1080/08870446.2017.1357815 
MEN'S ATTITUDES TO UV EXPOSURE AND FACIAL MORPHING

Skin Cancer Foundation. (2016). Skin Cancer Facts \& Statistics. Retrieved March, $8^{\text {th }}, 2017$ from http://www.skincancer.org/skin-cancer-information/skin-cancer-facts\#ethnicity

Sloan, C., Gough, B., \& Conner, M. (2010). Healthy masculinities? How ostensibly healthy men talk about lifestyle, health and gender. Psychology and Health, 25(7), 783-803

Stapleton, J. L., Manne, S. L., Darabos, K., Greene, K., Ray, A. E., Turner, A. L., \& Coups, E. J. (2015). Randomized Controlled Trial of a Web-Based Indoor Tanning Intervention: Acceptability and Preliminary Outcomes. Health Psychology, 34, 12781285. doi:10.1037/hea0000254

Strauss, A. \& Corbin, J. (1998) Basics of Qualitative Research Techniques and Procedures for Developing Grounded Theory. London: Sage.

Taylor, J., Murray, A., Lamont, A. (2017). Talking about sunbed tanning: Social representations and identity-work. Social Science \& Medicine. 184, 161-168. doi: 10.1016/j.socscimed.2017.05.020

Terry, G., Hayfield, N., Braun, V, Clarke, V. (2017). Thematic Analysis. In Willig, C. \& Stainton-Rogers, W. (Eds.). The Sage handbook of qualitative research in psychology 2nd edition (p. 17-37). London: SAGE Publications.

Thompson, E. \& Langendoerfer, K. (2015). Older men's blueprint for “Being a man”. Men and Masculinities, 19(2), 119-147, doi: 10.1177/1097184X15606949

Walsh, L. A., \& Stock, M. L. (2012). UV photography, masculinity, and college men's sun protection cognitions. Journal Of Behavioural Medicine, 35(4), 431-442.

Williams, A.L., Grogan, S., Clark-Carter, D., \& Buckley, E. (2013). Appearance-based interventions to reduce ultraviolet exposure and/or increase sun protection intentions and behaviours: A systematic review and meta-analyses. British Journal of Health Psychology, 18, 182-21. 
MEN'S ATTITUDES TO UV EXPOSURE AND FACIAL MORPHING

Williams, A.L., Grogan, S., Clark-Carter, D., \& Buckley, E. (2013). Men's experiences of an appearance-focussed facial-aging sun protection intervention: a qualitative study. Body Image. 10, 263-266.

Willig, C. (2013). Introducing qualitative research in psychology. $3^{\text {rd }}$ ed,. Berkshire: Oxford University Press. 